\title{
Short Communication \\ Clinical Trials of Coronary Stents in India: An Update
}

\section{*Corresponding author \\ Prashanth Srirangam, PhD \\ Manager \\ Department of Clinical Research \\ S3V Vascular Technologies Pvt Ltd \\ Vijayanagar $1^{\text {st }}$ Stage \\ Vijayanagar, Mysore 570012 \\ Karnataka, India \\ E-mail: prashanth.srirangam@gmail.com}

\section{Volume 3 : Issue 1}

Article Ref. \#: 1000HROJ3128

\section{Article History}

Received: June $9^{\text {th }}, 2016$

Accepted: June $29^{\text {th }}, 2016$

Published: June $30^{\text {th }}, 2016$

\section{Citation}

Srirangam P. Clinical trials of coronary stents in India: An update. Heart Res Open J. 2016; 3(1): 6-8. doi: 10.17140/HROJ-3-128

\section{Copyright}

(C2016 Srirangam P. This is an open access article distributed under the Creative Commons Attribution 4.0 International License (CC BY 4.0), which permits unrestricted use, distribution, and reproduction in any medium, provided the original work is properly cited.

\section{Prashanth Srirangam, PhD, M.Pharm, PGDCAQM, PGIPR}

Clinical Research, S3V Vascular Technologies Pvt Ltd, Mysore 570012, Karnataka, India

\section{ABSTRACT}

The Coronary Artery Disease (CAD) burden increased in Indian population and even it is increasing in young Indians. There are more ways to treat these patients and coronary stents are one of the option for them. In the present short communication I am presenting the number of trials, number of patients involved and the limitation of the trials conducted in Indian coronary artery disease patients.

KEYWORDS: Drug eluting stents; Coronary artery disease; National Interventional Council (NIC).

\section{INTRODUCTION}

In India the coronary artery disease (CAD) burden increased from last decade and the usage of coronary stents (bare metal and drug eluting Stents) increased. From National Interventional Council (NIC) 2016 data, it is evident that there are more than 4.75 lakhs coronary stents implanted in 2015 year in India and most of them are drug eluting coronary stents. ${ }^{1}$ Majority of these coronary stents were imported and having United States Food and Drug Administration (USFDA) approval and CE mark. As per Drugs and Cosmetics Act, stents are notified medical devices and as per Indian FDA rules if the device is having marketing approval and clinical trials in USA or EU, the same device can import to treat Indian patients without conducting any pre-market clinical investigations but need to conduct Post Market Surveillance (PMS) studies in India.

\section{DISCUSSION}

At present, there are more than 10 Indian medical devices companies manufacturing drug eluting coronary stents (ex. 3V NEIL from S3V Vascular Technologies Pvt. Ltd.) at affordable price to Indian CAD patients and some of them have CE mark and exporting to other countries. ${ }^{2}$

As per Clinical Trials Registry India (CTRI), hosted at the Indian Council of Medical Research's (ICMR's) National Institute of Medical Statistics (NIMS) (http://nims-icmr.nic.in), is a free and online public record system for registration of clinical trials being conducted in India that was launched on July $20^{\text {th }}, 2007$ (www.ctri.nic.in). Initiated as a voluntary measure, since June $15^{\text {th }}, 2009$, trial registration in the CTRI has been made mandatory by the Drugs Controller General of India (DCGI). ${ }^{3}$

From CTRI, I found there were 30 coronary stent clinical trials registered to date and a total of 13,934 patients involved in research. ${ }^{4-22}$

From the registered trials data set, it is evident that:

1. In 29 trials (96.77\%) the platform is metal (cobalt chromium or platinum chromium) and in one trial it is Bio-absorbable polymer and it is developed by an indigenous company.

2. The anti-restenotic drugs trend is moved from anti-cancer drugs like paclitaxel to limus 


\section{HEART RESEARCH}

derivatives and particularly in these Everolimus or Sirolimus dominating the market usage.

3. Only one trial is a proof of concept and rest are either registries or Post Marketing Surveillance (PMS) studies.

4. Most of the trials are initiated by sponsor and very less are investigator initiated and only one trial is a post-graduation thesis.

5. Design wise, most of the trials were single arm and very less are randomized control trials.

6. All the patients were followed-up either clinically or telephonically for at-least 1 year in most of the studies but in some studies, the patients were followed upto 6 years.

7. There are three trials recruited only diabetic patients and involves $25.69 \%(3580 / 13934)$ of total patients involved in all stent trials.

8. Twelve trials are initiated and sponsored by Indian medical device manufacturing companies and involve 1799 patients and it accounts $12.91 \%$ of total patients involved in coronary stent clinical trials.

9. Two trials are initiated by investigator and involves 2830 patients and it accounts $20.31 \%$ of total patients involved in coronary stent clinical trials.

10. Fifteen trials are initiated and sponsored by multinational medical device manufacturing companies (Foreign companies) and involve 9101 patients and it accounts $65.31 \%$ of total patients involved in coronary stent clinical trials.

\section{CONCLUSION}

From the Indian coronary stents clinical trials, we can say there is a much need to do more trials in CAD patients and these trials are very less when compared to other countries. The Foreign stent manufacture are conducting more clinical trials than Indian and best part from the trials is, the investigator initiated trials involves a good population and covers more regions of the country. There are more limitations observed in Indian manufacturers initiated trials and the major one is less sample size, so the further trials initiated by Indian manufacturers need to include a good sample size and power. Finally it is very clear that there is no specific guideline from Indian FDA (CDSCO) on PMS of coronary stents, but as per European or USFDA guidelines PMS are mandate and help the nation with the innovative products.

\section{REFERENCES}

1. Press Trust of India. Angioplasties performed in India rise by 42 pc in 2015: NIC. Web site. http://www.business-standard. com/article/pti-stories/angioplasties-performed-in-india-riseby-42-pc-in-2015-nic-116041600486_1.html. Accessed June 8,
2016

2. 3V NEIL. Sirolimus Drug Eluting Stent System. Web site. http://www.s3vvascular.com. Accessed June 8, 2016

3. National Institute of Medical Statistics. Clinical Trials Registry-India. Web site. http://ctri.nic.in/Clinicaltrials/advsearch. php. Accessed June 8, 2016.

4. Seth A, Patel TM, Stuteville M, et al. Three-year data from the XIENCE V INDIA study: safety and efficacy of XIENCE V in 1000 real world Indian patients. Indian Heart J. 2014; 66(3): 302-308. doi: 10.1016/j.ihj.2014.03.007

5. Rissam HS, Kishore S, Trehan N. Coronary artery disease in young Indians - The missing link. Indian Academy of Clinical Medicine. 2001; 2(3). Web site. http://medind.nic.in/jac/t01/i3/ jact01i3p128.pdf. Accessed June 8, 2016

6. Krishnan MN. Coronary heart disease and risk factors in India-On the brink of an epidemic? Indian Heart J. 2012; 64(4): 364-367. doi: 10.1016/j.ihj.2012.07.001

7. Sekhri T, Kanwar RS, Wilfred R, et al. Prevalence of risk factors for coronary artery disease in an urban Indian population. $B M J$ Open. 2014; 4: e005346. doi: 10.1136/bmjopen-2014-005346

8. Krishnan MN, Zachariah G, Venugopal K, et al. Prevalence of coronary artery disease and its risk factors in Kerala, South India: A community-based cross-sectional study. BMC Cardiovasc Disord. 2016; 16: 12. doi: 10.1186/s12872-016-0189-3

9. Chandra P, Kumar T. A prospective, multicenter, post marketing surveillance study to evaluate the safety and effectiveness of the Superia-Sirolimus Eluting Coronary Stent System (SSECSS) implanted during routine clinical practice in India. Indian Heart J. 2014; 66: 682-685. doi: 10.1016/j.ihj.2014.10.422

10. Patted SV, Halkatti P, Modi R. Effect of stent length on clinical outcome in patients with coronary artery disease. Indian Journal of Science and Technology. 2015; 8(4): 329-336. doi: $10.17485 / \mathrm{ijst} / 2015 / \mathrm{v} 8 \mathrm{i} 4 / 62284$

11. C.G. Bahuleyan, V.V. Krishna Kumar, ShifasBabu. Prospective study to evaluate safety and efficacy of Zotarolimus Eluting Stent (PSEZES) in patients with long coronary artery lesions. Indian Heart J. 2015; 67: 233-238. Web site. http://www.pubpdf. $\mathrm{com} / \mathrm{pub} / 26138180 /$ Prospective-study-to-evaluate-safety-andefficacy-of-Zotarolimus-Eluting-Stent-PSEZES-in-patients-wi. Accessed June 8, 2016

12. Sastry BK, Kumar N, Menon R, et al. Real world experience with an indigenously manufactured stent Cobal C-A retrospective study. Indian Heart J. 2014; 66: 525-529. doi: 10.1016/j. ihj.2014.08.015

13. Mehta AB, Chandra P, Dalal J, et al. One-year clinical out- 
comes of BioMatrix-Biolimus A9 eluting stent: The e-BioMatrix multicenter post marketing surveillance registry in India. Indian Heart J. 2013; 65: 593-599. doi: 10.1016/j.ihj.2013.08.031

14. Seth A, Hiremath S, Dani S, et al. Clinical outcomes with Biolimus (A9) eluting stent, 'BioMatrix' in diabetic patients Interim results from multicenter post market surveillance registry in India. Indian Heart J. 2013; 65: 586-592. doi: 10.1016/j. ihj.2013.08.030

15. Abhyankar AD, Thakkar AS. In vivo assessment of stent recoil of biodegradable polymer-coated cobalt-chromium sirolimus-eluting coronary stent system. Indian Heart J. 2012; 64: 541-546. doi: 10.1016/j.ihj.2012.07.005

16. Seth A, Chandra P, Chouhan NS, Thakkar AS. A first-in-man study of sirolimus-eluting, biodegradable polymer coated cobalt chromium stent in real life patients. Indian Heart J. 2012; 64: 547-552. doi: 10.1016/j.ihj.2012.07.011

17. Legutko J, Zasada W, Kałuża GL, et al. A clinical evaluation of the ProNOVA XR polymer free sirolimus eluting coronary stent system in the treatment of patients with de novo coronary artery lesions (EURONOVA XR I study). Indian Heart J. 2013; 65: 388-394. doi: 10.1016/j.ihj.2013.06.026

18. Rothman M. Resolute zotarolimus eluting stent for treatment of long coronary lesions. Indian Heart J. 2015; 67: 194-195. doi: 10.1016/j.ihj.2015.05.007

19. Stone GW, Abizaid A, Silber S, et al. Prospective, randomized, multicenter evaluation of a polyethylene terephthalate micronet mesh-covered stent (MGuard) in ST-segment elevation myocardial infarction: The MASTER trial. $J$ Am Coll Cardiol. 2012; 60: 1975-1984. doi: 10.1016/j.jacc.2012.09.004

20. Hiremath S, Chandra P, Desai D, et al. A prospective, multicentric, observational registry to evaluate performance of Excel $^{\mathrm{TM}} \mathrm{DES}$ in 'Real World, All Comers' patient population. Indian Heart J. 2014; 66: 691-695. doi: 10.1016/j.ihj.2014.12.009

21. Goyal BK, Kalmath BC, Kawar R, Sharma A, Khemnar B, Rangnekar H. Experience with BioMatrix BES and other DES in all-comers setting: A retrospective overview. Indian Heart J. 2013; 65: 678-682. doi: 10.1016/j.ihj.2013.10.014

22. Kaul U, Abhaichand R, Patel T, et al. A randomized comparison of taxus element vs. xience prime in Indian patients with diabetes mellitus (TUXEDO India). Indian Heart J. 2014; 66(Suppl 2): S104. doi: 10.1016/j.ihj.2014.10.289 